\title{
RECURSOS MINERAIS MARINHOS ALÉM DAS JURISDIÇÕES NACIONAIS
}

\author{
Kaiser G. de Souza
}

Received August 30, 2000 / Accepted September 11, 2001

\begin{abstract}
As três últimas décadas do século XX foram marcadas por uma intensa atividade relacionada à exploração dos recursos minerais localizados no leito dos oceanos além das juridições nacionais. Nos anos 70 e 80 , consórcios internacionais, constituidos por mais de 40 empresas de mineração, e agências governamentais provenientes de dezesseis países investiram centenas de milhões de dólares para localizar depósitos e estudar metodos de mineração e processamento de nódulos polimetálicos de leito marinho. Paralelamente, se desenrolou a III Conferência das Nações Unidas sobre o Direito do Mar. A Convenção das Nações Unidas sobre o Direito do Mar foi estabelecida em dezembro 1982 e em julho de 1994 foi adotado um acordo de implementação da Parte XI da Convenção, o qual regulamenta as atividades de aproveitamento dos recursos minerais localizados no leito dos oceanos além das juridições nacionais. O Acordo e a Parte XI da Convenção devem ser interpretados e aplicados como um instrumento único. A Convenção declara que os recursos minerais da área internacional dos oceanos são patrimônio comum da humanidade e cria a Autoridade Internacional dos Fundos Marinhos para organizar e controlar as atividades relativas ao aproveitamento destes recursos. Em meados dos anos 80, a situação econômica mundial se deteriorou face à desaceleração do crescimento industrial. Contudo, as empresas de mineração oceânica não se deixaram intimidar pela situação. No ponto de vista destas empresas, a posse de um sítio de mineração oceânica representa um capital financeiro, estratégico e político que vale a pena preservar. Nos anos 90, sete agências governamentais submeteram à Autoridade Internacional dos Fundos Marinhos seus planos de trabalho para exploração de nódulos polimetálicos. Até o presente momento seis delas já assinaram seus contratos de exploração junto à Autoridade. Desta forma, mais de $1.800 .000 \mathrm{~km}^{2}$ de áreas de exploração (equivalente a mais de $20 \%$ da superfície do território brasileiro) situadas nos oceanos Pacífico e Índico foram atribuídos a estas agências e à Autoridade para que esta possa conduzir suas próprias atividades de exploração. Atualmente a Autoridade está em vias de elaboração de regulamentos para a exploração de sulfetos polimetálicos e de crostas cobaltíferas situados no leito dos oceanos além das jurisdições nacionais. Logo que a Autoridade aprovar estes regulamentos, outras áreas também poderão ser determinadas para a exploração destes recuros. O começo do século 21 parece marcar o início de um esforço sistemático para o aproveitamento dos recursos minerais localizados no leito dos oceanos além das jurisdições nacionais. Este momento histórico requer uma especial atenção por parte das autoridades brasileiras no sentido de assegurar que os recursos minerais da parte internacional dos oceanos, especialmente aqueles localizados no Atlântico Sul, possam vir a constituir uma reserva econômica, estratégica e política para futuras gerações brasileiras.
\end{abstract}

Palavras-chave: Recursos minerais; Prospecção; Exploração; Mineração; Fundo oceânico; Convenção das Nações Unidas sobre o Direito do Mar; Autoridade International do Leito Marinho; Atlântico Sul; Brasil.

MARINE MINERAL RESOURCES BEYOND NATIONAL JURISDCTION LIMITS - The last three decades of the twentieth century were marked by intensive activities related to the development of mineral resources located in the seabed area beyond the limits of national jurisdiction. During the 70's and 80's, joint international ventures, including more than 40 mining companies and governmental agencies from 16 countries, spent hundreds of millions of dollars in locating deposits and studying methods for mining and 
processing the deep seabed polymetallic nodules. The Third United Nations Conferences on the Law of the Sea was held during the same period. In December 1982, the United Nations Convention on the Law of the Sea was adopted and in July 1994 the Aagreement Relating to the Implementation of Part XI of the Convention, which part regulates the activities in the international seabed area, was adopted. The Agreement and Part XI of the Convention shall be interpreted and applied together as a single instrument. The Convention stipulates that the mineral resources of the international seabed area are "common heritage of the mankind" and establishes the International Seabed Authority to organize and control the activities related to the development of these mineral resources. In the mid 80's, the world economic situation declined as a result of the decrease of industrial growth. However, the mining companies were not intimidated by the situation. In their eyes, the ownership of a mining site would represent a financial, strategic and political asset that deserved to be preserved. In the 90's, seven governmental agencies submitted to the International Seabed Authority their plans of work for exploration of polymetallic nodules. As of today, six of them have already signed their contracts for exploration with the Authority. As a result, more than $1,800,000 \mathrm{~km}^{2}$ of exploration areas (more than $20 \%$ of the surface of Brazil) located in the Pacific and Indian Oceans were allocated to these governmental agencies and to the Authority to carry out exploration activities. At the present time, the Authority is in the process of developing regulations for prospecting and exploration for hydrothermal polymetallic sulphides and cobaltrich ferromanganese crusts located in seabed areas beyond national jurisdiction. As soon as the Authority approves these regulations, other areas may be allocated for the exploration of these resources. The beginning of the twenty-first century seems to mark the commencement of a systematic effort to develop the mineral resources located in the seabed area beyond the limits of national jurisdiction. This historical event requires a special attention from the Brazilian authorities to ensure that the international seabed mineral resources, especially those located in the South Atlantic Ocean, will constitute an economic, strategic and political asset for future Brazilian generations.

Key words: Seabed mineral resources; Prospecting; Exploration; Mining; UN Convention on the Law of the Sea; International Seabed Authority; South Atlantic; Brazil.

International Seabed Authority 1

14-20 Port Royal Street - Kingston, Jamaica

Tel.: +1 (876) 9229105 Fax.: +1 (876) 9220195

E-mail: kdesouza@isa.org.jm

\section{INTRODUÇÃO}

O interesse econômico pelos recursos minerais da área internacional dos oceanos começou nos anos 50 quando John Mero, pesquisador da Universidade de Berkeley (USA) analisou a rentabilidade dos depósitos de nódulos polimetálicos localizados no leito marinho (Mero, 1959). John Mero demonstrou que:

$\S$ o teor em níquel dos nódulos era igual ou superior ao das jazidas terrestres lateríticas pobres, as quais vinham sendo aproveitadas;

$\S$ o teor em cobre nos nódulos era superior ao dos porfiritos cupríferos já explorados naquela época;

$\S$ o teor em cobalto era similar ao de certos depósitos em fase de produção;

$\S$ o teor em manganês era similar ao das jazidas australianas que estavam em vias de serem aproveitadas.

Entretanto, foi somente em meados dos anos 60 que as indústrias de mineração começaram a se interessar por esta fonte potencial de metais, se lançaram na prospecção, e passaram a estudar os sistemas de explotação e tratamento metalúrgico dos nódulos polimetálicos.

A tomada de consciência do valor econômico que poderiam ter os nódulos polimetálicos localizados no leito marinho e a intensificaçao das atividades visando o aproveitamento destes recuros conduziu o 
Presidente dos Estados Unidos, Lyndon Johnson, a se manisfestar, em 1966, contra a possibilidade da criação de "uma nova forma de competição colonial entre as potências marítimas" e contra "uma corrida desmesurada para a utilização dos leitos marinhos além das jurisdições nacionais". O Presidente Johnson afirmou, nesta ocasião que os leitos marinhos são e deveriam permanecer a "herança de todo o ser humano".

Em 1967, o Embaixador Arvid Pardo, representante de Malta, chamou a atenção da Assembléia Geral das Nações Unidas sobre a possível apropriação dos leitos marinhos por parte dos Estados tecnologicamente avançados e colocou em pauta o conceito revolucionário de "patrimônio comum da humanidade" em se referindo a todos os recuros minerais, incluindo hidrocarbonetos, situados além das jurisdições nacionais. Em 1970, a Assembléia Geral das Nações Unidas adotou a Declaração de Princípios (resolução 2749, XXV), na qual declara que leito dos oceanos e seu subsolo situado além das jurisdições nacionais, assim como seus recursos minerais são patrimônio comum da humanidade.

Os anos 70 e 80 foram marcados por uma intensa atividade relacionada ao futuro do aproveitamento dos recursos minerais marinhos. Várias empresas de mineração foram formadas e atuaram intensamente na prospecção de nódulos polimetálicos e no desenvolvimento de sistemas de mineração e beneficiamento dos metais de valor econômico contidos nos nódulos.

As previsões de algumas empresas de mineração indicavam um retorno anual de investimento da ordem de $35 \%$ na explotação dos nódulos polimetálicos. Estas estimativas, as quais se revelaram extremamente otimistas, alarmaram os países produtores dos metais de valor econômico (níquel, cobre, cobalto e manganês) existentes nos nódulos. Em conseqüência, eles exerceram uma forte pressão nas negociações realizadas durante a III Conferência das Nações Unidas sobre o Direito do Mar. Como resultado, mais da metade do texto final da Convenção das Nações Unidas sobre o Direito do Mar se refere à gestão dos recursos minerais do leito marinho situados além das jurisdições nacionais.

\section{PROSPECÇÃO DE NÓDULOS POLIMETÁLICOS DO LEITO MARINHO}

O início das atividades de prospecção de nódulos polimetálicos de leito marinho foi marcado pelo envolvimento de mais de 40 empresas de mineração provenientes de dezesseis países diferentes (Lenoble, 1996).

Quatro consórcios foram formados nos Estados Unidos entre 1974 e 1977 :

- Kennecott Consorcium (KCON) criado em janeiro de 1974, incluindo uma empresa americana, duas inglesas, uma japonesa e uma canadense;

- Ocean Mining Associates (OMA), formado em 1974 por duas empresas americanas, uma belga e cinco japonesas;

- Ocean Management Incorporated(OMI), fundada em 1975 por uma empresa canadense, quatro alemães e dezenove japonesas;

- Ocean Minerals Company (OMCO), formada em 1977 por duas empresas americanas e uma holandesa.

Na França, a Sociedade Le Nickel e o Centro National para a Explotação dos oceanos (CNEXO, transformado mais tarde em IFREMER) se associaram em 1970 para conduzirem as primeiras prospecções no sul do oceano Pacífico. Em 1974, o Comissariado para Energia Atômica (CEA - França) e o Estaleiro de France Dunkerque se associaram aos precedentes para formarem a Associação Francesa para o Estudo e a Prospecção de Nódulos IFREMER-AFERNOD.

A partir do início dos anos 80 os russos iniciaram uma prospecção sistemática no oceano Pacífico utilizando navios de grande porte. Em 1985 eles constituíram uma empresa de mineração para nódulos polimetálicos (YUZHMORGEOLOGIYA), a qual, contando com mais de 1200 funcionários, desenvolveu vários equipamentos especialmente adaptados à prospecção dos nódulos.

O Japão criou em 1982 uma empresa de mineração, Deep Ocean Research and Development (DORD), a qual agrupava 49 organismos, incluindo alguns que já faziam parte dos consórcios formados 
nos Estados Unidos.

A Índia começou a prospecção do oceano Índico no início dos anos 80, contando com meios técnicos da Alemanha. Em seguida, desenvolveu sua própria competência para continuar seus trabalhos por conta própria.

Em meados dos anos 80, vários países socialistas, incluindo Polônia, Bulgária, Cuba, República Checa, República Eslovaca e Federação Russa, constituiram um consórcio internacional (Interoceanmetal-IOM), para prospectar nódulos no oceano Pacífico Central. Os anos 80 também a China e a Córeia constituiram suas empresas para exploração de nódulos polimetálicos.

Com exceção da Índia que desenvolveu suas atividades no oceano Índico, todos os outros países concentraram suas atividades de prospecção no oceano Pacífico onde os nódulos apresentam um teor mais elevado de níquel e cobre.

\section{CONVENÇÃO DAS NAÇÕES UNIDAS E SOBRE O DIREITO DO MAR E O ACORDO DE IMPLEMENTAÇÃO DA PARTE XI DA CONVENÇÃO}

A Convenção das Nações Unidas Sobre o Direito do Mar (Convenção) é o resultado de 9 anos de negociações entre centenas de países durante a III Conferência das Nações Unidas sobre o Direito do Mar.

A Convenção foi posta para assinatura em 1982. De forma geral, ela estabelece seis espaços marinhos, medidos a partir das linhas de base:

- o mar territorial que se prolonga até 12 milhas náuticas;

- a zona contígua que pode se estender por 12 milhas náuticas após o mar territorial;

- a zona econômica exclusiva que tem seu limite exterior fixado em 200 milhas náuticas;

- a plataforma continental que, dependendo da localização do talude continental ou da espessura sedimentar, pode se estender até de 350 milhas náuticas ou até 100 milhas náuticas a partir da isóbata de 2500 metros;

- o alto mar, situado além da zona econômica exclusiva dos países costeiros; e

- a zona internacional do leito marinho, denominada Area, a qual se situa além das jurisdições nacionais.

Nos termos da Convenção, a Área inclui o leito do mar, os fundos marinhos, e o seu subsolo além do limite das jurisdições nacionais". A Área e seus recursos minerais são declarados pela Convenção como patrimônio comum da humanidade. Assim sendo, todos os direitos sobre estes recursos minerais devem pertencer a humanidade. A Convenção estabelece ainda que as atividades na Área devem ser organizadas, realizadas e controladas pela Autoridade Internacional dos Fundos Marinhos (Autoridade) em nome da humanidade em geral.

Nenhum Estado ou Pessoa Jurídica, singular ou coletiva, poderá reivindicar, adquirir ou exercer direitos relativos aos minerais extraídos da Área, a não ser de conformidade com a Parte XI da Convenção, a qual regulamenta as atividades na Área.

Algumas das disposições da Parte XI da Convenção estabeleciam que países e empresas que se lançassem na explotação de recursos minerais marinhos na Área deveriam transferir tecnologia e financiar operações de explotação por parte da Autoridade, através de sua Empresa, em nome dos países em desenvolvimento.

Em vista destas disposições, 17 países, na maioria países desenvolvidos, se abstiveram de assinar a Convenção impedindo desta forma sua universalização. Segundo os países desenvolvidos, estas disposições eram inaplicáveis economicamente e penalizavam consideravelmente as empresas que poderiam vir a explotar os recursos minerais da Área.

Um acordo de implementação da parte XI da Convenção foi então negociado entre os países em desenvolvimento e os países desenvolvidos. Adotado em 1994, o acordo tinha como objetivo inicial assegurar que a Autoridade fosse estabelecida sob as bases de um custo mínimo de funcionamento, visto que a explotação dos recursos minerais da Área não se tornariam realidades nos próxinos $15 / 20$ anos. $\mathrm{O}$ Acordo também modificou as disposições consideradas inaceitáveis por parte dos países desenvolvidos. O Acordo e a Parte XI da Convenção devem ser interpretados e aplicados juntos como um instrumento único.

Com a adoção do Acordo de implementação 
da Parte XI (Acordo), a Convenção pode entrar em vigor em 16 de novembro de 1994. A Autoridade Internacional dos Fundos Marinhos foi então estabelecida. Sua sede é situada em Kingston, na Jamaica.

\section{SITUAÇÃO ECONÔMICA E JURÍDICA DAS EMPRESAS DE MINERAÇÃO OCEÂNICA}

No início dos anos 80 as inúmeras atividades realizadas pelas empresas de mineração já indicavam que o custo de desenvolvimento e funcionamento de uma explotação de nódulos polimetálicos no leito marinho seria superior ao retorno financeiro decorrente da venda dos metais extraídos. Esta constatação surgiu ao mesmo tempo em que o preço dos metais começou a cair vertiginosamente atingindo os mínimos históricos (Lenoble, 1996).

$\mathrm{Na}$ realidade, a situação econômica havia mudado em face da desaceleração do crescimento industrial mundial. Contudo, as empresas de mineração oceânica não se deixaram intimidar pela situação. A posse de um sítio de mineração oceânica representa um capital financeiro e estratégico que vale a pena preservar.

Os industriais norte americanos fizeram pressão sobre seu governo para que medidas conservadoras fossem tomadas. Em junho de 1980 foi então adotado o Deep Seabed Hard Mineral resources Act estabelecendo que as empresas americanas poderiam prospectar e mais tarde explotar os depósitos de nódulos polimetálicos situados além das jurisdições nacionais. Esta iniciativa unilateral foi seguida pelo Reino Unido, Alemanha, França e Rússia.

Naquela ocasião, as negociações sobre o direito do mar ainda se desenrolavam de forma complexa. A Convenção foi estabelecida em 1982, mas somente em 1994 foi concluído o Acordo de Implementação da Parte XI da Convenção, o qual regulamenta as atividades de aproveitamento dos recursos minerais localizados na Área. Apesar do acordo de implementação, os Estados Unidos não ratificaram a Convenção. Portanto, os sítios de mineração que foram atribuídos pelo governo americano a suas empresas de mineração não foram reconhecidos pela Autoridade Internacional do Leito Marinho.

Desde então, sete empresas de mineração submeteram à Autoridade, segundo os termos da Convenção, os seus planos de trabalho para a exploração de nódulos polimetálicos. Assim sendo, estas empresas receberam o status especial de « Investidores Pioneiros » em exploração de nódulos polimetálicos, conferindo-lhes assim certos privilégios.

Os Investidores Pioneiros são :

- Department of Ocean Development - DOD (Governo da Índia);

- Institut Français de Research pour l'Exploitation de la Mer e Association Française pour l'Étude et la Recherche des Nodules - IFREMER/AFERNOD (França) ;

- Yuzhmorgeologiya (Federação Russa) ;

- Deep Ocean Resources Development Co. Ltd. - DORD (Japão) ;

- China Ocean Mineral Resources Research and Development Association - COMRA (China);

- Korean Deepsea Resources Research Center - KORDI (Governo da Corea)

- Interoceanmetal Joint Organization-IOM (Polônia, Bulgária, República Checa, República Slováca, Cuba e Federação Russa).

Nos termos da Convenção cada investidor pioneiro tem o direito a uma área de exploração que não deve exceder $75.000 \mathrm{~km}^{2}$. Os pioneiros que até o momento da submissão do seu plano de trabalho não tiverem concluído a delimitação destes 75.000 $\mathrm{km}^{2}$ poderão reivindicar até $150.000 \mathrm{~km}^{2}$, mas deverão, no espaço de 8 anos restituir o excedente. A Convenção também determina que cada investidor pioneiro delimite uma outra área de mesmo tamanho e valor econômico, a qual passa a ser considerada como "área reservada" para atividades pela Autoridade. Desta forma, mais de $1.800 .000 \mathrm{~km}^{2}$ dos leitos marinhos do oceano Pacífico e Índico foram atribuídos aos investidores pioneiros e à Autoridade. Esta área representa o equivalente a mais de $20 \%$ da superfície do território brasileiro. A figura 1 mostra a localização dos sítios de exploração situados no oceano Pacífico. 


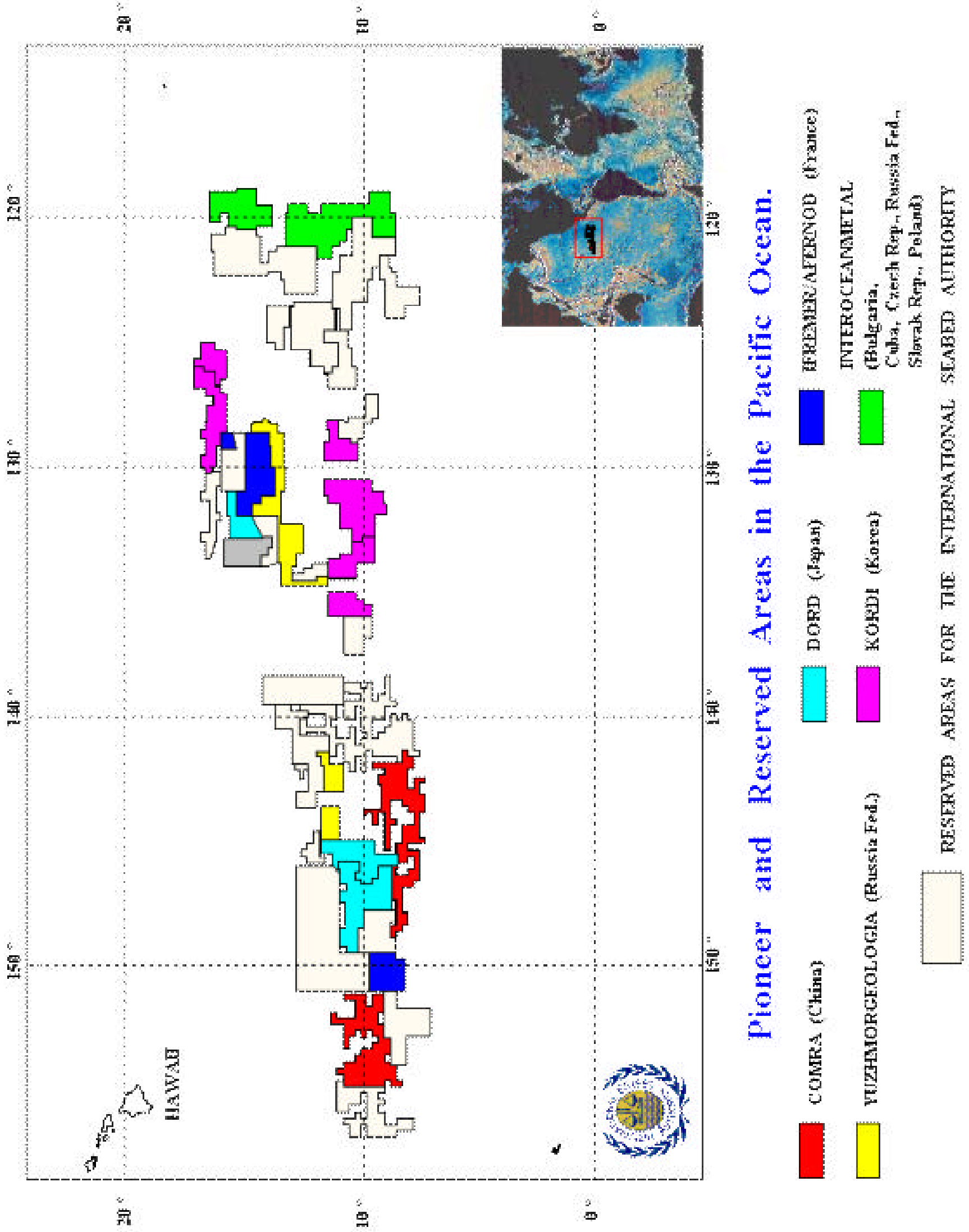

Figura 1 - Localização dos sítios de exploração de nódulos polimetálicos situados no oceano Pacífico. 


\section{AUTORIDADE INTERNACIONAL DOS FUNDOS MARINHOS (AUTORIDADE)}

A Autoridade é a organização por intermédio da qual os Estados Partes da Convenção organizam e controlam as atividades com vista ao aproveitamento dos recursos minerais localizados na “Área”.

\section{Constituição}

Ela é constituída de uma Assembléia, de um Conselho, de uma Comissão Jurídica e Técnica, de um Comitê de Finanças, de sua "Empresa" e de seu Secretariado. A Assembléia é composta por todos os membros da Autoridade. Em julho de 2001 ela contava com 135 Estados Partes e 57 Estados Observadores.

O Brasil é Estado Parte da Autoridade desde o seu estabelecimento em 1994. A delegação brasileira junto à Autoridade é chefiada por um membro do Ministério das Relações Exteriores e conta com representantes da Secretaria da Comissão Interministerial de Recursos do Mar (SECIRM), do Estado Maior da Armada (EMA), do Departamento Nacional de Produção Mineral (DNPM) e da Petrobras.

O Conselho é constituído por 36 membros dentre os Estados Partes eleitos pela Assembléia. Eles representam 5 grupos de interesse:

- Grupo A constituído por quatro membros consumidores de minerais que venham a ser extraídos da Área;

- Grupo B constituído por quatro membros que, diretamente ou por parte dos seus nacionais, tenham feito os maiores investimentos na preparação e na realização de atividades na Área;

- Grupo C composto por quatro membros que, na base da produção nas áreas sob sua jurisdição, sejam grandes exportadores líquidos das categorias de minerais que venham a ser extraídos da Área;

- Grupo D constituído por seis membros dentre os Estados Partes em desenvolvimento, que representam interesses especiais (grande população, estados sem litoral ou em situação geográfica desfavorecida, grandes importadores das categoriais de minerais que venham a ser extraídos da Área, produtores potenciais de tais minerais, e países menos desenvolvidos);

- Grupo E composto por dezoito membros eleito de modo a assegurar o princípio de uma distribuição geográfica eqüitativa dos lugares do Conselho no seu conjunto. Para tal efeito as regiões geográficas devem ser: África, América Latina e Caribe, Europa Ocidental e outros estados, e Europa Oriental.

O Brasil é membro do Conselho desde sua formação em 1996. Sua presença, como integrante do grupo (E) está assegurada até 2004 quando novas eleições serão feitas pela Assembléia.

Os membros do Comitê de Finanças e a da Comissão Jurídica e Técnica são selecionados pelo Conselho, baseado na competência técnica e no princípio da repartição geográfica dos candidatos.

O Secretariado da Autoridade compreende um Secretário Geral que é assessorado por 17 profissionais internacionais qualificados nos domínios científicos, técnico, administrativo e legal e por 18 funcionários locais. O Secretariado tem como função geral assessorar os outros órgãos da Autoridade.

A Empresa é o órgão da Autoridade que tem como função realizar atividades visando o aproveitamento dos recursos minerais da Área. Estas atividades incluem extração, transporte, processamento e comercialização.

Entretanto, o Acordo de Implementação da Parte XI da Convenção estabelece que a Empresa passará a ser operacional somente quando o primeiro plano de explotação de recursos minerais da Área por parte de uma outra empresa for aprovado pela Assembléia da Autoridade ou quando o Conselho receber uma aplicação para a realização de operações conjuntas com a Empresa. Enquanto a Empresa não for operacionalizada, a Secretaria da Autoridade exerce suas funções em conformidade com o Acordo de Implementação da Parte XI da Convenção.

\section{Viabilidade econômica}

Durante os três primeiros anos de sua existência, $o$ aporte financeiro da Autoridade era proveniente das 
Nações Unidas. A partir de 1997 a Autoridade passou a ser financiada pelos seus Estados Partes. A escala de contribuição anual dos membros da Autoridade é baseado numa fração da escala de cotas de contribuição das Nações Unidas. O orçamento que foi votado para o ano 2001 corresponde a US\$ 5.253.200. Os cinco maiores contribuidores são em ordem decrescente o Japão (25\%), a Alemanha (15\%), a França (10\%), Itália (8\%), o Reino Unido (8\%). O Brasil contribui com um montante de US\$ 111.700 , ou seja, $2.26 \%$ do orçamento anual da Autoridade.

\section{Programa de trabalho}

Desde a entrada em vigor da Convenção em 1994, a Autoridade concentrou seus esforços, de um lado no estabelecimento de seus órgãos e do outro lado na realização de seu mandato (Odunton and DeSouza, 2000).

Um dos primeiros grandes resultados do trabalho dos órgãos da Autoridade foi o estabelecimento dos regulamentos que governam a prospecção e a exploração de nódulos polimetálicos da área internacional dos oceanos. Estes regulamentos, os quais estão disponíveis na web page da Autoridade ${ }^{2}$, formam as bases legais necessárias para a aprovação de planos de trabalho para exploração de nódulos polimetálicos. Eles contêm igualmente várias provisões referentes à proteção do meio ambiente marinho.

A elaboração destes regulamentos possibilitou, até o presente momento, a assinatura dos contratos de exploração por parte de seis dos sete investidores pioneiros.

A Autoridade aprovou igualmente uma série de diretrizes para o levantamento do possível impacto ambiental resultante da exploração de nódulos polimetálicos por parte dos contratantes. Estas recomendações incluem o estabelecimento de zonas de referência, implementação de programa de monitoramento, submissão de informações específicas, e responsabilidades por impacto ambiental.

De acordo com seus regulamentos, a Autoridade também tem como função monitorar as atividades a serem desenvolvidas pelos contratantes. Ela tem igualmente concentrado esforços na avaliação dos depósitos de nódulos polimetálicos existentes nas zonas reservadas para suas próprias atividades.

A Autoridade promoveu vários workshops para tratar com a comunidade científica internacional e empresas de mineração oceânica sobre assuntos relacionados ao aproveitamento dos recursos minerais da área internacional dos oceanos.

O primeiro workshop ${ }^{3}$ lidou com questões relativas ao possível impacto ambiental proveniente da exploração de nódulos polimetálicos. $\mathrm{O}$ workshop teve como resultado a elaboração de recomendações referentes à utilização do meio ambiente marinho por parte dos contratantes. O segundo workshop ${ }^{4}$ se concentrou nos aspectos relativos ao desenvolvimento tecnológico importante para as atividades de explotação de nódulos polimetálicos. O terceiro workshop 5 procurou consolidar informações sobre ocorrência, parâmetros técnicos e interesse econômico dos depósitos de diferentes recursos minerais marinhos, tais como sulfetos polimetálicos, crostas cobaltíferas, hidratos de gás, fosforitas marinhas e metais preciosos. Este workshop também teve como objetivo trazer informações aos Estados Membros para facilitar a redação de regulamentos para a exploração destes recursos. O quarto workshop ${ }^{6}$ se concentrou nas questões relativas à padronização de métodos para coleta, análise e processamento de dados e informações relativas a recursos minerais marinhos.

A Autoridade deverá realizar no ano de 2002, um workshop para tratar da cooperação científica e tecnológica referente ao aproveitamento de recursos minerais marinhos. Ela deverá também se concentrar na elaboração de regulamentos para a exploração de sulfetos polimetálicos e crostas cobaltíferas da zona internacional dos oceanos.

Ao mesmo tempo, Autoridade está desenvolvendo sua base de dados referentes às ocorrências dos diferentes tipos de recursos minerais marinhos. Esta base de dados será posta à disposição dos Estados Membros via internet.

\section{OUTROS RECURSOS MINERAIS DE LEITO MARINHO}

Em 1998, Governo da Federação Russa requisitou oficialmente à Autoridade que adote regras 
e regulamentos para a exploração de sulfetos polimetálicos e de crostas cobaltíferas, dois tipos de recursos minerais que ocorrem na Área.

Atualmente, os sulfetos polimetálicos têm atraído mais a atenção de indústrias de mineração do que os nódulos polimetálicos. Alguns sítios de interesse econômico já foram identificados no Oceano Pacífico. Quanto às crostas cobaltíferas, elas já foram bem estudadas em vários oceanos. No Atlântico Sul elas são bem conhecidas na Elevação do Rio Grande (alto topográfico situado na parte oceânica em frente ao estado do Rio Grande do Sul). Segundo as informações provenientes de workshops sobre diferentes recursos minerais marinhos promovidos pela Autoridade, intensas pesquisas sobre sulfetos e crostas vêm sendo realizadas por dezenas de países.

\section{IMPORTÂNCIA POLÍTICO-ESTRATÉGICA DOS RECURSOS MINERAIS DA PARTE INTERNACIONAL DOS OCEANOS}

Dezenas de empresas de mineração proveniente de 16 países se envolveram diretamente, nas últimas décadas, na prospecção de nódulos polimetálicos no leito marinho. Até o presente momento, mais de $1.800 .000 \mathrm{~km}^{2}$ de áreas de títulos de mineração já foram emitidos no Oceano Pacífico e no Oceano Índico para exploração destes recursos. Entretanto, os especialistas no assunto afirmam que a explotação de nódulos polimetálicos não é economicamente viável.

Atualmente a Autoridade está em vias de elaboração de regras e regulamentos internacionais para a exploração de sulfetos polimetálicos e de crostas cobaltíferas que ocorrem na Área. Logo que a Autoridade concluir a elaboração destes regulamentos, outras áreas de mineração também poderão ser requisitadas para exploração de sulfetos e crostas, incluindo áreas no Atlântico Sul, situadas em frente à plataforma continental brasileira.

Se analisarmos o interesse de certos países pelos recursos minerais marinhos de mar profundo veremos que o fator econômico é o menos importante. Se algum país se lançar na explotação destes recursos, talvez não venha a ganhar muito com os recursos explotados, ao menos em curto prazo, mas sem dúvida terá uma tecnologia de ponta de intervenção marinha para vender, alugar ou adaptar para outras necessidades.

É importante lembrar que $95 \%$ dos oceanos não têm profundidades maiores do que 6.000 metros. Os países que desenvolverem uma tecnologia para explotação de nódulos polimetálicos entre $4.000 \mathrm{e}$ 6.000 metros de profundidade terão conquistado os oceanos sob o ponto de vista tecnológico e estratégico.

É importante também lembrar que todas a ilhas que existem no planeta fazem parte da soberania de algum país. Isto envolve, portanto a criação de zonas econômicas exclusivas em torno destas áreas, como previsto na Convenção das Nações Unidas pelo Direito do Mar, 1982.

Agora, os altos topográficos que não são muito profundos passam a ter um interesse estratégico para os países que queiram firmar sua presença em qualquer oceano. Provavelmente nas próximas décadas, muitos altos topográficos serão requisitados para exploração de recursos minerais marinhos. Um exemplo de alto topográfico que apresenta grande interesse estratégico é a Elevação do Rio Grande, situada na zona oceânica em frente ao estado do Rio Grande do Sul e de Santa Catarina. Esta elevação chega a apenas 800 metros de profundidade, enquanto sua base está situada a mais ou menos 4.000 metros de profundidade.

Os oceanos constituem as últimas fronteiras políticas, estratégicas e econômicas do planeta. É importante ter em mente que as empresas que reivindicarem áreas de mineração oceânica deverão também poder contar com a proteção das forças armadas de seus países de origem. Este fato pode modificar o equilíbrio militar em vários oceanos.

\section{ÁREAS DE INTERESSE DE PESQUISA MINERAL PARA O BRASIL NO ATLÂNTICO SUL}

A presença do Brasil no Atlântico Sul é uma questão político-estratégica que envolve o bem-estar de futuras gerações. Esta presença pode e deve ser preparada agora da melhor maneira possível. Uma das maneiras de prepará-la é através da requisição de áreas de mineração oceânica situadas além do limite exterior da plataforma continental brasileira. $\mathrm{O}$ limite exterior da plataforma continental brasileira equivale agora ao que foi a para o Brasil a linha do 
Tratado de Tordesilhas. Ir além deste limite agora significa garantir a presença do Brasil no Atlântico Sul de forma eficaz.

Os geólogos marinhos brasileiros estão profissionalmente capacitados para realizarem um programa de levantamento de recursos minerais das áreas situadas além dos limites da plataforma continental brasileira, no Atlântico sul. Para tal, as autoridades brasileiras devem disponibilizar os recursos necessários.

Tal programa, além de produzir as informações necessárias para preparar a posição do Brasil junto a Autoridade Internacional do Leito Marinho e marcar sua presença no Atlântico Sul, poderia também reforçar o Programa de Avaliação da Potencialidade Mineral da Plataforma Continental Jurídica Brasileira (REMPLAC), o qual é coordenado pelo Ministério das Minas e Energia no âmbito da Comissão Interministerial para os Recursos de Mar (CIRM).

Sob o ponto de vista geológico, três diferentes regiões podem ser vistas como ponto de partida para a pesquisa de recursos minerais em oceano profundo:

$\S$ A primeira seria a região da zona econômica exclusiva e plataforma continental do Arquipélago São Pedro-São Paulo. Este arquipélago, situado a $1100 \mathrm{~km}$ da costa do Estado do Rio Grande do Norte, é parte do território brasileiro. Esta região é o único lugar sob a jurisdição brasileira onde existe cordilheira mesoceânica e, conseqüentemente a possibilidade de ocorrências de sulfetos polimetálicos. Atividades de pesquisa destes recursos nesta região pode ao mesmo tempo reforçar os princípios do Programa Arquipélago (PROARQUIPELAGO) desenvolvido pela Comissão Interministerial para os Recursos do Mar (CIRM) com o objetivo de estudar e de ocupar esta distante parte do território brasileiro. A ocorrência de sulfetos polimetálicos nas proximidades desta região é conhecida na literatura geológica internacional.

$\S$ A segunda região inclui a zona econômica exclusiva e plataforma continental da Ilha da Trindade e regiões oceânicas adjacentes. Este parece ser um bom ponto de partida para a pesquisa de nódulos polimetálicos.

$\S$ A terceira região compreende a Elevação do Rio Grande. Este é sem dúvida o lugar onde a pesquisa de crostas cobaltíferas deveria começar, sem esquecer todos os montes submarinos que ocorrem na margem central brasileira e também os montes submarinos da Cadeia Vitória-Trindade.

\section{CONCLUSÃO}

Nas últimas décadas, dezenas de empresas de mineração e agências governamentais provenientes de vários países se envolveram em atividades relacionadas ao aproveitamento de nódulos polimetálicos localizados em áreas oceânicas além das jurisdições nacionais. Mais de $1.800 .000 \mathrm{~km}^{2}$ de áreas de exploração (equivalente a mais de $20 \%$ da superfície do território brasileiro) situadas no oceano Pacífico e Índico já foram atribuídas a sete agêncies governamentais e à Autoridade Internacional dos Fundos Marinhos para que esta possa conduzir suas próprias atividades de exploração de nódulos polimetálicos.

Enquanto a Autoridade concentra seus esforços atualmente na elaboração de regulamentos para a exploração de sulfetos polimetálicos e de crostas cobaltíferas, várias outras empresas de mineração e agências governamentais se lançam na pesquisa destes recursos minerais com vista a sua viabilidade econômica e estratégica. Desta forma, o começo do século 21 parece marcar o início de um esforço sistemático para o aproveitamento dos recursos minerais marinhos. Este momento histórico requer uma especial atenção por parte das autoridades brasileiras no sentido de assegurar que os recursos minerais marinhos localizados no Atlântico Sul possam vir a constituir uma reserva econômica, estratégica e política para futuras gerações brasileiras.

A presença do Brasil no Atlântico Sul deve ser garantida agora e da melhor maneira possível. Uma das maneiras de preparar esta presença é através da requisição de áreas de mineração oceânica situadas além dos limites da plataforma continental juridical brasileira. Para tal, o Brasil deve dispor da capacidade instalada em suas instituições de pesquisa e lhes garantir os meios necessários. 


\section{AGRADECIMENTOS}

O autor agradece ao Professor Sidney Luiz de Matos Mello pelo convite para a participar no Seminário sobre Recuros Minerais Marinhos realizado em Agosto de 2000 no LAGEMAR; à Fundação de Apoio e Amparo à Pesquisa do Estado do Rio de Janeiro (FAPERJ) e Sociedade Brasileira de Geofísica (SBGf) pelo financiamento para participar do Seminário; e aos companheiros do LAGEMAR pela acolhida calorosa durante o Seminário. O autor também agradece ao Secretário Geral da Autoridade Internacional do Leito Marinho, Embaixador Satya Nandan, pela autorização para publicar este artigo; ao Dr. Walter Leitão de Sá e ao Professor Sidney Mello pela revisão da primeira versão do texto do artigo e ao CF (RRm) Alexandre Tagore Albuquerque pelas observações.

\section{REFERÊNCIAS}

LENOBLE, J.P., 1996. Les nodules Polymetallic: Bilan de 30 Ans de Travaux dans le Monde. Chronique de la Recherche Minière, 524, 1996.

MERO, J.L., 1959. The mining and processing of deep-sea manganese nodules. Berkeley, California, USA, Institut of Marine Resources, 312p.

ODUNTON, N.A.\& DESOUZA, K.G., 2000. The International Seabed Authority's Technical Activities in Respect of the Development of Mineral Resources in the International Seabed Área, $31^{\circ}$ International Congress of Geology, Rio de Janeiro, Brazil. 15 August, 2000.
${ }^{1}$ Este artigo é de responsabilidade do autor e não representa necessariamente o ponto de vista da Autoridade Internacional do Leito Marinho. The views expressed herein are those of the author and do not necessarily reflect the views of the International Seabed Authority.

${ }^{2}$ http://www.isa.org.jm/

3 Proceedings of the International Seabed Authority Workshop on Deep-Seabed Polymetallic Nodules Exploration: Development of Environmental Guidelines. Sanya, Hainan Island, People's Republic of China, 1-5 June 1998.

${ }^{4}$ Proceedings of the International Seabed Authority Workshop on Proposed Technologies for Deep Seabed Mining of Polymetallic Nodules. Kingston, Jamaica, 3-6 August 1999.

5 Proceedings of the International Seabed Authority Workshop on the Other Mineral Resources then Polymetallic Nodules. Kingston, Jamaica, 26-30 June 2000.

${ }^{6}$ Proceedings of the International Seabed Authority Workshop to Standardize the Environmental Data and Information Required by the Authority's Mining Code and Recommendations for Contractors (in preparation). Kingston, Jamaica, 25-29 June 2001.

\section{NOTE ABOUT THE AUTHOR}

\section{KAISER GONÇALVES DE SOUZA}

Nascido em Recife, é geólogo formado em 1984 na Universidade do Vale do Rio dos Sinos (UNISINOS), no Rio Grande do Sul. Especializou-se em geologia marinha e completou o doutorado na Universidade de Paris, em 1991. Concluiu o pós-doutorado no Instituto de Geociências e Recursos Naturais em Hannover, Alemanha em 1993. Realizou pesquisas em tectônica de placas e formação de crosta oceânica, com especialização no Atlântico Sul. Fez treinamento em exploração de recursos minerais marinhos patrocinado pela Comissão Preparatória da Autoridade Internacional do Leito Marinho e do
Tribunal Internacional das Leis do Mar (Nações Unidas). Especializou-se em assuntos relativos à Convenção das Nações Unidas sobre o Direito do Mar e trabalhou como especialista em recursos marinhos no Ministério da Ciência e Tecnologia e com a Comissão Interministerial de Recursos do Mar, em Brasília. Atualmente trabalha como geólogo marinho na Autoridade Internacional do Leito Marinho em Kingston, Jamaica, onde contribui para o desenvolvimento de atividades visando o aproveitamento de recursos minerais marinhos localizados em áreas oceânicas além das jurisdições nacionais. 


\section{HISTÓRICO DOS EVENTOS DA SBGf}

$1^{\circ}$ Encontro Regional da Sociedade Brasileira de Geofísica

Novembro de 1985

São José dos Campos, SP

Resumos -1 volume

$2^{\circ}$ Encontro Regional da Sociedade Brasileira de Geofísica

Agosto de 1987

Salvador, $\mathrm{Ba}$

$1^{\circ}$ Congresso da Sociedade Brasileira de Geofísica

20 a 24 de novembro de 1989

Rio de Janeiro, RJ - Brasil

Anais - 3 Volumes

$2^{\circ}$ Congresso Internacional da Sociedade Brasileira de Geofísica

27 de novembro a $1^{\circ}$ de dezembro de 1991

Salvador, Bahia - Brasil

Anais - 2 Volumes

$3^{\circ}$ Congresso Internacional da Sociedade Brasileira de Geofísica

07 a 11 de novembro de 1993

Rio de Janeiro, RJ - Brasil

Anais - 2 Volumes

$4^{\circ}$ Congresso Internacional da Sociedade Brasileira de Geofísica \& $1^{\circ}$ Conferência da União Latino-

Americana de Geofísica

20 a 24 de agosto de 1995

Rio de Janeiro, RJ - Brasil

Anais - 2 Volumes

$5^{\circ}$ Congresso Internacional da Sociedade Brasileira de Geofísica

28 de setembro a 02 de outubro de 1997

São Paulo, SP - Brasil

Anais - 2 Volumes

$6^{\circ}$ Congresso Internacional da Sociedade Brasileira de Geofísica

19 de agosto de 1999

Rio de Janeiro, RJ - Brasil

Publicação em CD

$7^{\circ}$ Congresso Internacional da Sociedade Brasileira de Geofísica

28 a 31 de Outubro de 2001

Centro de Convenções da Bahia - Salvador, Bahia - Brasil

Maiores Informações: www.salvador2001.sbgf.org.br ou sbgf@sbgf.org.br

$8^{\circ}$ Congresso Internacional da Sociedade Brasileira de Geofísica

Programado para Setembro de 2003

RIOCENTRO - Rio de Janeiro, RJ

Maiores Informações: sbgf@sbgf.org.br 